\title{
LOS AGRICULTORES Y SUS NUEVAS PRIORIDADES: EXIGIR UNA EDUCACIÓN ÚTIL, PROFESIONALIZARSE Y DEPONER EL INDIVIDUALISMO
}

\section{FARMERS AND THEIR EMERGING PRIORITIES: TO ASK FOR A USEFUL EDUCATION, PROFESSIONALIZE AND FORSAKE INDIVIDUALISM}

\section{Lacki Polan}

PolanLacki@terra.com.br

Rua Bispo Dom José, 2051 apto. 706

Tel: (55-41) 3243-2366. Celular: (55-41) 9602-1239

80440-080 Curitiba - Paraná - Brasil

E-Mail: PolanLacki@uol.com.br / PolanLacki@onda.com.br

Websites: www.polanlacki.com.br / www.polanlacki.com.br/agroesp

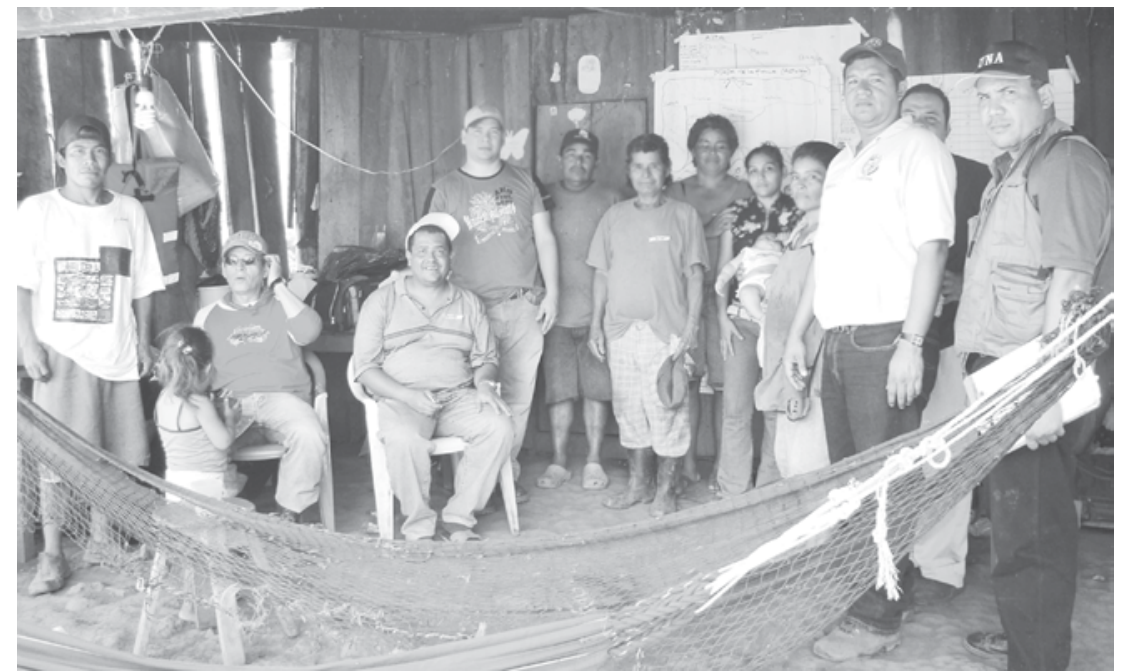

$\mathrm{P}$ ara empezar, una pregunta y una invitación a los educadores rurales y a los agricultores A los educadores: $\mathrm{Si}$ en el agro latinoamericano tenemos tan extraordinarias potencialidades para producir riquezas, en muchas regiones durante los 365 días del año, ¿por qué tenemos tantos agricultores tan pobres y por qué ellos mismos no logran superar su pobreza? Una respuesta que, debido a su extraordinaria importancia, no podemos seguir ignorando es la siguiente: porque nadie les enseñó, concreta y objetivamente, qué y cómo deben hacer para generar más riquezas e ingresos familiares. Entonces, si la "problemática" de fondo es el no saber y el no saber hacer, la "solucionática" de fondo tiene que consistir en proporcionar a los pobres rurales el saber y el saber hacer para que puedan ser más eficientes y más productivos, aun cuando sus factores de producción sean aparentemente muy limitados. Partiendo de esta premisa, son los educadores rurales y sus respectivas instituciones quienes tienen que asumir este desafío de mejorar, de manera muy significativa, la calidad y la funcionalidad de nuestro debilitado sistema público de educación rural, el no formal y el formal en los tres niveles. Entre otras razones, porque los educadores rurales sencillamente no tienen a quién delegar esta noble tarea. Esto significa que si ellos no la asumen nadie lo hará y seguiremos siendo pobres y subdesarrollados rurales; por más tierra, maquinaria, riego, créditos, refinanciaciones y condonaciones de deudas y subsidios que los gobiernos proporcionen a los habitantes del campo.

A los agricultores. La Monsanto con la Cargill y la Nestlé con la Fonterra de Nueva Zelanda (que es la más grande empresa exportadora mundial de lácteos) tuvieron que constituir alianzas estratégicas para poder fortalecerse y competir en los mercados globalizados. Algo similar están haciendo los gigantes económicos tales como: los bancos, los fabricantes de vehículos y maquinaria agrícola, las industrias farmacéuticas, 
las empresas productoras de fertilizantes, pesticidas y semillas híbridas o genéticamente modificadas etc.). Si estas gigantescas corporaciones multinacionales necesitan juntarse para mejorar su competitividad, ¿cómo podrán sobrevivir económicamente los minúsculos, dispersos y frágiles agricultores, si insisten en su ancestral individualismo y se recusan a practicar el cooperativismo y la solidaridad entre ellos?

En los países de América Latina tenemos crecientes evidencias de que la principal causa del fracaso económico de la mayoría de los productores rurales reside en las ineficiencias que ellos mismos y/o sus empleados, involuntariamente y hasta sin darse cuenta, cometen en las distintas etapas del negocio agrícola. Y, como regla general, ellos siguen cometiéndolas principalmente debido a la insuficiencia, inadecuación y obsolescencia de los conocimientos y competencias que poseen. Basta con visitar las zonas rurales de América Latina para constatar que muchísimos productores rurales están empobrecidos y endeudados, no necesariamente porque no tengan acceso a más tierra, más maquinaria o animales de producción, sino porque su propia mano de obra, su tierra y sus animales tienen bajísima productividad $\mathrm{o}$ rendimiento. $\mathrm{Y}$ esto ocurre fundamentalmente porque nuestras instituciones educativas rurales no les enseñaron cómo aplicar de manera correcta medidas "eficientizadoras" para aumentar los rendimientos por hectárea y por animal, para reducir los costos por kilogramo producido, para mejorar la calidad de sus cosechas, para reducir las pérdidas durante y después de la cosecha (físicas y de calidad) y para obtener mejores precios en la venta de sus excedentes al incorporarles valor y al comercializarlos con menor intermediación.

¿Premiar las ineficiencias con subsidios o eliminarlas con conocimientos? Consecuentemente dichas ineficiencias no necesitan y no deben ser contrarrestadas, año tras año a través de subsidios, sino que deben ser evitadas, corregidas y/o eliminadas proporcionando a los agricultores una educación útil y funcional que esté clara y explícitamente orientada a que sean más eficientes, más productivos, más emprendedores, más profesionalizados y más cooperativos con sus vecinos. En este último aspecto los agricultores tendrán que deponer el individualismo y practicar la solidaridad entre ellos. Muy especialmente, para facilitar la solución de aquellos problemas de interés común que no les convenga solucionarlos en forma individual (compra de insumos, producción comunitaria de raciones balanceadas, formación de grupos de inseminación artificial, adquisición y uso de maquinaria en común, incorporación comunitaria de valor y comercialización de sus cosechas, etc. ). Por todas estas razones es el sistema de educación rural el que debe corregir sus evidentes debilidades, disfuncionalidades e ineficiencias en la formación y capacitación de los recursos humanos que intervienen en el proceso de desarrollo agrícola y rural. Porque, sin lugar a dudas, son estas falencias del sistema educativo las principales causantes de los fracasos económicos de los agricultores y de la pobreza imperante en las zonas rurales. Gobiernos populistas logran perpetuarse en el poder engañando a los agricultores. En la era de la globalización de los mercados, no hay tiempo para seguir filosofando y teorizando. Nuestros agricultores están siendo obligados a "eficientizarse", como pre requisito para poder competir con los productores rurales más eficientes del mundo. $\mathrm{Y}$ dicha "eficientización" no se logra por la vía de los subsidios y otras medidas paternalistas que más bien premian a los ineficientes en vez de adoptar adecuadas medidas educativas para volverlos más eficientes. Por esta razón, en el mundo contemporáneo, el éxito económico de nuestros agricultores depende mucho más de su eficiente desempeño técnicoproductivo, gerencial y comercial, que de las improbables e ineficaces decisiones políticas de gobiernos populistas. Seguir creyendo en la utopía del paternalismo es una ingenuidad de la que los productores rurales necesitan escapar inmediatamente; entre otras razones porque en nuestra América Latina, durante más de 55 años, esos mismos programas asistencialistas han demostrado ser sinónimos de sucesivos fracasos y de gigantescos derroches de recursos públicos.

Por todos estos antecedentes, y sin dilación, es imperativo que los productores rurales se organicen, no para mendigar créditos y subsidios perpetuadores de dependencias, sino con miras a exigirles a sus respectivos gobiernos una formación/capacitación mucho más eficiente y funcional de sí mismos y de sus familias, con dos objetivos bien explícitos: (a) para que ellos, al "eficientizarse", puedan emanciparse de los efímeros y excluyentes subsidios gubernamentales y (b) para que puedan ser menos vulnerables ante los otros integrantes de las cadenas agroalimentarias (banqueros y usureros, fabricantes y vendedores de insumos y maquinaria, especuladores, transportistas, compradores, industrializadores y revendedores de sus cosechas, etc.) quienes actualmente se apropian de un exagerado porcentaje de las riquezas que los agricultores producen en sus fincas.

Quienes trabajan y arriesgan muchísimo reciben el 20\%.y los otros el $80 \%$. En muchos casos los agricultores reciben apenas el $20 \%$ de los precios que los consumidores finales pagan por los alimentos, después de que las agroindustrias o los supermercados los fraccionan y realizan un muy superficial "maquillaje" en sus cosechas; maquillaje que los propios agricultores, de forma individual o grupal, podrían y deberían realizar en sus propias fincas y comunidades. Y no lo hacen por falta de espíritu asociativo para encarar en grupos las siguientes actividades: adquirir los insumos en conjunto, para producir las propias raciones balanceadas en vez de comprárselas a las multinacionales, para no endeudarse en la adquisición de maquinaria individual sobredimensionada, para reducir los costos por kilogramo producido, para mejorar la calidad de sus cosechas e incorporarles valor agregado y, finalmente, para venderlas en conjunto y con menor intermediación. Todo lo anterior con el objetivo de que ellos (y no los agroindustriales 
y "supermercadistas") se apropien de un porcentaje más elevado y más justo de las riquezas que producen en sus fincas. Si lo hiciesen, seguramente, no recibirían apenas el $20 \%$.

$\begin{array}{llrrr}\text { Una propuesta construida } & \text { desde } & \text { abajo } & \text { hacia } \\ \text { arriba } y \text { desde adentro } & \text { hacia fuera. } & \text { Este }\end{array}$ diagnóstico y esta propuesta educativa-asociativaemancipadora han sido construidos a partir:

a) de los ejemplos, positivos y negativos, que he visto con mis propios ojos en miles y miles de fincas, comunidades y mercados rurales, escuelas primarias/ fundamentales rurales, agencias de extensión agrícola y facultades de ciencias agrarias de 19 países de América Latina, en los cuales he ejecutado mis actividades profesionales. El haber vivido estas realidades concretas, directamente en terreno, me permitió constatar que existe la siguiente y clarísima disfuncionalidad y contradicción: entre el qué y el cómo nuestro sistema de educación está enseñando a los extensionistas agrícolas, a los futuros maestros de las escuelas fundamentales rurales, a los agricultores, a sus empleados y a los niños de las escuelas primarias rurales y el qué y el cómo ellos deberían aprender para poder desempeñarse en el medio rural, con la eficiencia requerida por los tiempos modernos. b) de las contundentes y cada vez más frecuentes críticas a nuestro sistema educativo rural, que me envían muchísimos de los 270.000 interlocutores electrónicos con quienes estoy permanentemente intercambiando opiniones e informaciones sobre estos temas.

No más reformas educativas cosméticas y demagógicas. En consecuencia de lo anteriormente descrito, si queremos enfrentar con seriedad, realismo y objetividad la erradicación de la pobreza y del subdesarrollo rural, debemos empezar por una inmediata, radical y profunda (no cosmética como la hemos llevado a cabo hasta la fecha) reforma en los contenidos curriculares, en los métodos pedagógicos y en la profesionalización de los directores y supervisores de las siguientes instituciones educativas: Facultades de educación o pedagogía y escuelas normales, facultades de ciencias agrarias, escuelas fundamentales/primarias rurales y servicios gubernamentales de asistencia técnica y extensión rural. En ellas residen las causas más profundas de los problemas, angustias y sufrimientos de los habitantes rurales y en ellas deberán adoptarse las medidas correctivas para adecuarlas a las verdaderas necesidades de los habitantes del campo. 